\title{
Metabolic and Genetic Studies of a Family with Ornithine Transcarbamylase Deficiency
}

\author{
Arnold S. Goldstein, Nigholas J. Hoogenraad, John D. Johnson, Keiko Fukanaga, \\ Elizabeth Swierczewski, Howard M. Cann, and Philip Sunshine ${ }^{[39]}$ \\ Section of Developmental Medicine, Department of Pediatrics, Stanford University Medical Center, Stanford, California, USA
}

\begin{abstract}
Extract
We have described a patient with ornithine transcarbamylase (OTC) deficiency. The clinical course and pedigree substantiate the X-linked transmission of the defect with varying degrees of illness in females. Because orotic aciduria accompanied hyperammonemia in the patient, orotic acid was measured as an indication of a partial OTC deficiency after ammonia and protein loading in members of the patient's family. Both the mother, an obligate carrier, and an aunt, the only symptomatic female in this pedigree, had hyperammonemia after the ingestion of ammonium chloride. They also had significant orotic aciduria after a protein load as did the two female cousins whose ammonium tolerance was normal. The maternal grandmother excreted a large amount of orotic acid in her urine relatively consistently. These data suggest that the two female cousins and the maternal grandmother are asymptomatic female heterozygotes despite their normal ammonium loading tests.
\end{abstract}

\section{Speculation}

Protein loading in the form of a relatively palatable and innocuous meal, followed by determination of orotic acid content in urine, may prove to be a sensitive, noninvasive, and easy means to identify female carriers of ornithine transcarbamylase deficiency.

\section{Introduction}

Hyperammonemia which resulted from a deficiency of hepatic ornithine transcarbamylase (carbamoyl phosphate: $x$-ornithine carbamoyl transferase; EC. 2.1.3.3) has been recognized with increasing frequency since the defect was first described by Russell and coworkers in $1962[4-7,10,12-15,18,19,22-24,26,29]$. The known pedigrees suggest that the gene coding for this enzyme may be X-linked, and that the deficiency is lethal in males and results in a variable degree of clinical severity in affected females [4-7, 12-15, 22-26, 29]. The only male in which the disorder has not been fatal apparently had a variant form of the disease [14].
Because of the variable manifestations of the disorder in females, and the severity in males, it would be of great value to detect the female carriers of the defect. In previous studies, assays of ornithine transcarbamylase (OTC) in liver tissue obtained by biopsy have been utilized in an attempt to identify the heterozygote, but even in an obligate carrier, the specific activity of the enzyme may be normal [26]. Ammonia determination after oral administration of ammonium chloride has also been employed to detect the carrier state, but the validity of this procedure is subject to the variability intrinsic to the assay of ammonia: Because patients with OTC deficiency have been reported 
to excrete increased concentrations of both orotic acid and proline in their urine $[5-7,13,15,18,19,29]$, we have investigated the possibility that the determination of these two compounds may be utilized to detect the heterozygous carriers of OTG deficiency.

\section{Patients}

A pedigree of the family is illustrated in Figure 1. The proband of this study, patient $I I I-8$, was delivered after an uneventful pregnancy and weighed $3,430 \mathrm{~g}$ at birth. His mother had previously delivered two normal males, and had one spontaneous abortion. Her next pregnancy resulted in the birth of a male infant who was normal until 7 days of age when he began to have seizures and respiratory distress. He expired on the following day. Sixteen months later she delivered another male infant who followed a similar course and expired at 7 days of age. Analysis of his urine by gas chromatography revealed an elevated concentration of orotic acid. Concentrations of amino acids, carbohydrates, and other organic acids in urine and plasma were normal. A tentative diagnosis of OTC deficiency was made despite the fact that the liver of the infant was not available for enzymatic assay.

The mother conceived once again, and a diagnostic amniocentesis was carried out at 14 weeks of gestation. The concentration of orotic acid in amniotic fluid was normal, and the fetus was shown to be a male. Cells cultured from amniotic fluid grew poorly and had to be nurtured in culture media consisting of $30 \%$ calf serum. Neither these cultured cells nor cells grown from amniocenteses obtained from other patients were found to have OTC activity. We were unable to assess prenatally whether the infant would or would not be affected. The parents, cognizant of the data, decided that the mother would carry the infant to term.

The proband was a perfectly healthy appearing male infant who nursed well and demonstrated no clinical abnormalities. Concentrations of ammonia in blood, and urea, orotic acid, proline and ammonia in urine were determined daily, and were within normal limits during the first 6 days of life except that orotic acid started to rise above normal levels on day 5. On the 7th day, the infant became lethargic, nursed poorly, and the concentration of orotic acid in urine was found to be increased markedly to $6 \mathrm{mg} / 24 \mathrm{hr}$ (Fig. 2). That morning the concentration of ammonia was also elevated to $660 \mu \mathrm{g} / 100 \mathrm{ml}$ blood. Protein feedings were eliminated, but within hours the infant began to have hyperventilation and seizures. Neomycin was given orally and per rectum, and peritoneal dialysis was initiated. The concentration of ammonia in blood began to fall, and the infant's seizures were controlled. Citric acid (300 $\mathrm{mg} / 24 \mathrm{hr}$ ) was infused in an attempt to remove ammonia by reaction with the tricarboxylic acid cycle intermediate, $\alpha$-ketoglutarate. Both phenobarbital and ethinyl estradiol were given to the infant in an attempt to increase the activity of hepatic OTC. Twenty percent glucose with small amounts of free amino acids was infused to prevent protein catabolism. Despite these measures, the patient expired at 25 days of age.

Postmortem examination revealed edema of the peritoneal surfaces, which was secondary to chronic peritoneal dialysis. The liver was grossly pale, but the weight and microscopic features were normal. The thymus was small and depleted of lymphocytes and eosinophiles. The brain and other organs of the body were essentially normal. Besides the apparent distress caused by prolonged peritoneal dialysis, malnutrition

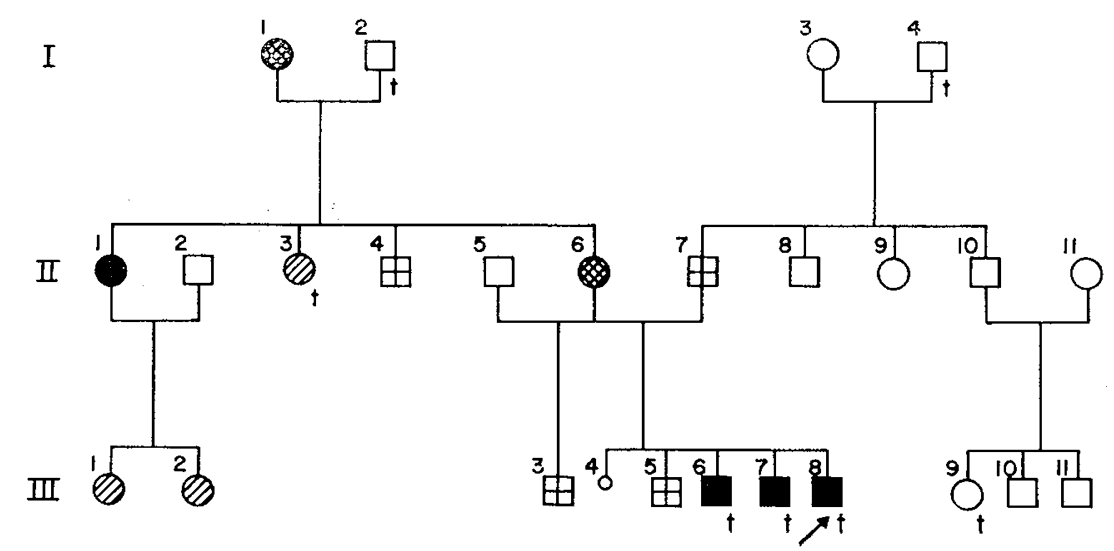

Fig. 1. Pedigree. $\bigcirc:$ female; $\nearrow$ : proband; obligate carrier; $\boxplus$ : tested, normal; $\square:$ male; $\uparrow:$ died; $\emptyset$ : possible carrier; : proven or presumed ornithine carbamylase deficiency. 

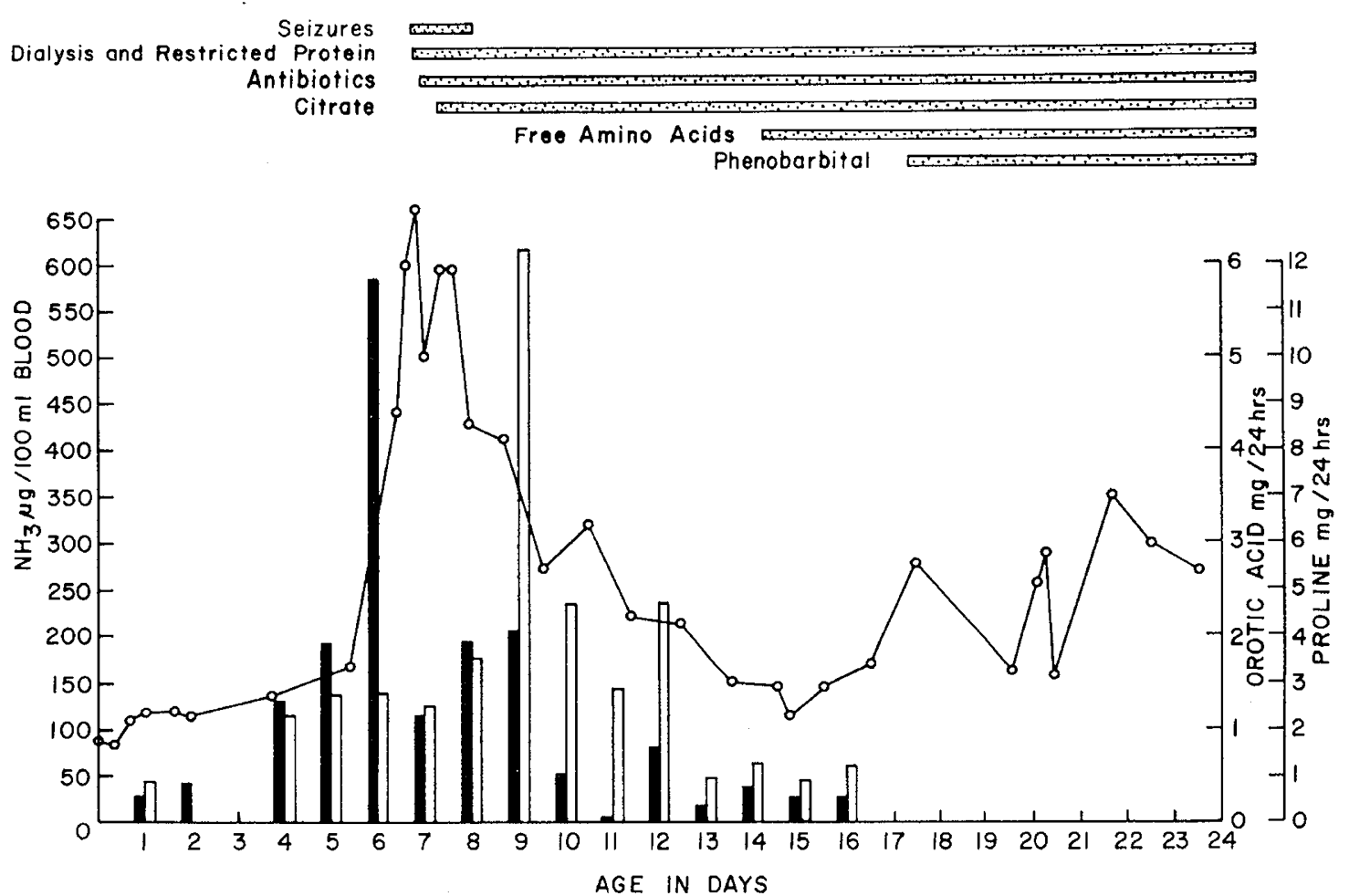

Fig. 2. Summary of clinical and biochemical course of proband. $\bigcirc-O:$ ammonia $(\mu \mathrm{g} / 100 \mathrm{ml}$ blood); $\mathrm{hr})$; $\square$ : proline in urine $(\mathrm{mg} / 24 \mathrm{hr}$ ).

was also likely to have been an important factor in contributing to the patient's demise.

\section{Family Members}

The mother, II-6, is a healthy, 33-year-old woman who has never had any adverse symptoms after protein ingestion.

A maternal aunt, $I I-3$, died at 13 months of age of presumed encephalitis with convulsions and coma. Undiagnosed liver and brain abnormalities were present at autopsy.

Another maternal aunt, $I I-I$, is the only relative with symptoms suggestive of OTC deficiency [10, 13, 22, 25, 29]. She voluntarily limits her protein intake, but when given a large protein meal or when given oral ammonium chloride, she became acutely ill with abdominal pain, nausea, vomiting, dizziness, and migraine-like headaches.

The daughters of this aunt, $I I I-1$ and $I I I-2$, are 10 and 13 years of age, respectively, and are asymptomatic.

The proband's father, $I I-7$, maternal grandmother, $I-1$, and maternal uncle, $I I-4$, have never had symptoms likely to be related to OTG deficiency.

A paternal cousin, $I I I-9$, died at 3 weeks of age of sudden infant death syndrome.

\section{Methods}

\section{Analytical Procedures}

1. Blood ammonia was determined on heparinized venous blood. Specimens were immediately placed on ice, and ammonia was measured within $20 \mathrm{~min}$ by the Bessman modification of the Seligson method [2].

2. Urine orotic acid was determined using a modification of the method of Adachi et al. [1]. Inasmuch as urine contains compounds capable of producing high blanks [21], the method of Adachi et al. was modified as follows. (1) It was found necessary to double the amount of $p$-dimethylaminobenzaldehyde used in determining the orotic acid content of urine because of its rapid consumption by urine reactants. Consequently, $2 \mathrm{ml} \mathrm{5 \%}$ p-dimethylaminobenzaldehyde was used per $1 \mathrm{ml}$ urine. (2) The high urine blank obtained in this colorimetric procedure occurs without bromination, whereas color development due to orotic acid does not. Consequently, duplicate samples were processed; one was brominated, the other was not and acted as a blank for the former sample. Using these two modifications, orotic acid could be accurately determined if present at a concentration between 1 and $25 \mu \mathrm{g}$ orotic acid/ml urine. Results of single specimens 
were expressed as a ratio to creatinine (as measured by Jaffe's method [8]).

3. Urine proline was determined by the method of Troll et al. [20].

\section{Enzyme Aasays}

Tissues used for enzyme assays were obtained within $2 \mathrm{hr}$ of death and stored in liquid nitrogen until analyzed.

Urea cycle enzymes were assayed using $10 \%$ tissue homogenates prepared in $0.25 \mathrm{~m}$ sucrose using a PotterElvehjem homogenizer. Carbamyl phosphate synthetase, ornithine transcarbamylase, argininosuccinic acid synthetase, argininosuccinic acid lyase, and arginase were assayed by methods described previously [29]. Because the colorimetric assay for OTG revealed no activity in tissues from the proband, a more sensitive radiochemical technique was devised. In this method, the conversion of $\left({ }^{14} \mathrm{C}\right)$ carbamyl phosphate [32] to $\left({ }^{14} \mathrm{C}\right)$ citrulline was measured as follows: undiluted homogenates from the proband's tissues were incubated for $5 \mathrm{~min}$ at $37^{\circ}$ in a total volume of $0.5 \mathrm{ml}$. The concentration of ornithine was $10 \mathrm{~mm},\left({ }^{14} \mathrm{C}\right)$ carbamyl phosphate concentration was $0.2 \mathrm{~mm}$, and the reaction was carried out in $50 \mathrm{~mm}$ glycylglycine buffer, $\mathrm{pH} 8.3$. The reaction was terminated by adding $0.3 \mathrm{ml}$ of $1 \mathrm{M}$ $\mathrm{HClO}_{4}$, and the resulting mixture was heated for 3 min in a boiling water bath (this will decompose excess $\left({ }^{14} \mathrm{C}\right)$ carbamyl phosphate to ${ }^{14} \mathrm{CO}_{2}$ and inorganic phosphate). Excess ${ }^{14} \mathrm{CO}_{2}$ from the decomposition of $\left({ }^{14} \mathrm{C}\right)$ carbamyl phosphate was removed by adding crushed Dry Ice. $\left({ }^{14} \mathrm{C}\right)$ Citrulline formed during the incubation was isolated as follows: $0.3 \mathrm{ml}$ of $10 \mathrm{mM} \mathrm{L}$ citrulline was added as carrier and the mixture was placed on a small column (1 by $2 \mathrm{~cm}$ ) of Dowex $50-\mathrm{H}^{+}$ in a disposable 5 -ml syringe. The column was washed four times with $5 \mathrm{ml}$ water and the citrulline was eluted with $1-\mathrm{ml}$ lots of $0.5 \mathrm{~m}$ ammonium acetate. The fractions containing citrulline were combined, mixed, and the radioactive content of a $1-\mathrm{ml}$ aliquot was measured in Aquasol [33] using a Beckman LS 233 liquid scintillation spectrometer [34].

All enzyme assays were linear for the duration of the incubation and less than $5 \%$ of the limiting substrate was consumed.

\section{Loading Tests}

1. Ammonium loading tests were carried out by oral administration of solid $\mathrm{NH}_{4} \mathrm{Cl}$ in gelatin capsules. Adults were given $3 \mathrm{~g}$ and the two children, ages 9 and 12 years, $2 \mathrm{~g}$. The concentration of ammonia in blood was determined before the administration of $\mathrm{NH}_{4} \mathrm{Cl}$ and at 1, 2, and $4 \mathrm{hr}$ thereafter. Orotic acid in urine was determined before and in the subsequent two urine samples collected after the ingestion of $\mathrm{NH}_{4} \mathrm{Cl}$.

2. The patients ingested a meal containing $1 \mathrm{~g}$ protein $/ \mathrm{kg}$ body wt. A fasting urine sample and each urine specimen for the ensuing several hours were assayed for the concentration of orotic acid.

\section{Results}

\section{Studies on Proband (III-8)}

The assays of the activities of urea biosynthetic enzymes of autopsy material obtained from III-8 confirm the diagnosis of OTC deficiency (Table I). The activity of OTC in liver, brain, and intestine was less than $1 \%$ of that measured in tissues obtained from normal patients. At $\mathrm{pH} 7.0$, the activity of the enzyme was negligible, being $0.02 \%$ of normal values obtained at that $\mathrm{pH}$. The activities of the other enzymes of the urea cycle were comparable with controls.

The chemical abnormalities noted in this infant were similar to those reported in other infants with OTC deficiency. The concentration of ammonia in blood, and the concentrations of orotic acid and proline in urine began to increase on the infant's 5 th day of life and became abnormal on the 6th day. Alterations in orotic acid preceded those of ammonia, but were consistently parallel (Fig. 2). The concentrations of proline in urine varied more than those of orotic acid and were not regarded as being valuable indicators of a deficiency of urea biosynthesis. Although

Table $I$. Activities of urea cycle enzymes ${ }^{1}$

\begin{tabular}{lccc}
\hline & \multicolumn{1}{c}{ Proband } & Control & $\begin{array}{c}\% \text { of mean } \\
\text { control } \\
\text { value }\end{array}$ \\
\cline { 2 - 3 } & $\mu \mathrm{mol} / \mathrm{hr} / \mathrm{g}$ wet wt & 140 \\
\hline $\begin{array}{l}\text { Carbamyl phosphate } \\
\quad \text { synthetase }\end{array}$ & 84 & $48 / 72$ & \\
$\begin{array}{l}\text { Ornithine transcarbam- } \\
\quad \text { ylase }\end{array}$ & & & \\
$\quad \begin{array}{l}\text { Liver } \\
\text { Brain }\end{array}$ & 0.71 & $10,400 / 7,680$ & 0.008 \\
$\quad \begin{array}{l}\text { Intestinal mucosa } \\
\text { Argininosuccinate syn- } \\
\text { thetase }\end{array}$ & 0.06 & 160 & 0.04 \\
Argininosuccinate lyase & 0.21 & 320 & 0.07 \\
Arginase & 59.4 & $5.6 / 3.4$ & 140 \\
& 3,480 & $3,360 / 4,704$ & 86 \\
\end{tabular}

1 Activity of the enzymes of the urea cycle were measured as described in Methods. Control tissues were obtained from two male infants who died from respiratory failure and multiple congenital anomalies, respectively. 
Table II. Ammonium chloride loading test ${ }^{1}$

\begin{tabular}{|c|c|c|c|c|c|c|}
\hline & \multicolumn{3}{|c|}{ Ammonia in blood, $\mu \mathrm{g} / 100 \mathrm{ml}$} & \multicolumn{3}{|c|}{ Orotic acid in urine, $\mu \mathrm{g} / \mathrm{ml}$ creatinine } \\
\hline & Fasting & $\mathrm{NH}_{4} \mathrm{Cl}$ load & $\begin{array}{l}\mathrm{NH}_{4} \mathrm{Cl} \text { load } \\
\text { minus fasting }\end{array}$ & Fasting & $\mathrm{NH}_{4} \mathrm{Cl}$ load & $\begin{array}{c}\mathrm{NH}_{4} \mathrm{Cl} \text { load } \\
\text { minus fasting }\end{array}$ \\
\hline Control subjects & $111 \pm 9.7$ & $119 \pm 4.2$ & $9.6 \pm 15.2$ & $4.1 \pm 2.31$ & $4.6 \pm 1.25$ & $0.3 \pm 2.72$ \\
\hline$I I-6$ (mother) & 119 & 143 & 24 & 5.7 & 5.7 & 0 \\
\hline$I I-7$ (father) & 119 & 121 & 2 & & 0.9 & \\
\hline$I-1$ (maternal grandmother) & 114 & 126 & 12 & 12.1 & 13.9 & 1.8 \\
\hline$I I-I$ (maternal aunt) & 81 & 211 & 131 & 1.7 & 16.0 & 14.3 \\
\hline$I I I-1$ (daughter of $I I-1$ ) & 72 & 103 & 31 & 0.8 & 8.3 & 7.5 \\
\hline$I I I-2$ (daughter of $I I-I)$ & 61 & 83 & 22 & & 9.2 & \\
\hline
\end{tabular}

1 The ammonia value after loading was the highest of the three samples taken. Control values were obtained from five healthy, un. related adult subjects. The control value of ammonia after loading was calculated by averaging the highest value obtained in the three samples from each control subject. The differences between each control subject's maximum and fasting values were also averaged. Control values are given as the mean \pm SD.

the blood urea nitrogen rose to a peak of $11 \mathrm{mg} / 100$ $\mathrm{ml}$ blood at 1 week of age, the concentration soon fell and remained below $5 \mathrm{mg} / 100 \mathrm{ml}$ thereafter.

Peritoneal dialysis was effective in lowering the concentration of ammonia in blood and also alleviated some of the infant's symptoms. Death, although forestalled, could not be prevented.

\section{Family of $I I I-8$}

The ammonia loading test (Table II) resulted in a mild but significant increase in the concentration of ammonia in blood of the proband's mother, $I I-6$, at 2 $\mathrm{hr}$, and a marked increase at $\mathrm{l} \mathrm{hr}$ in a maternal aunt, II-1 (who became acutely ill with symptoms of headache, nausea, and abdominal pain and was debilitated for a 2-week period). None of the other subjects developed significant hyperammonemia during the $4 \mathrm{hr}$ of the test. The concentration of orotic acid in urine increased to 3-4 times those of control subjects in the aunt, $I I-1$; and both of her daughters, $I I I-1$, and $I I I-2$, had 2 times the concentration of orotic acid in their urine after the load as did the control subjects. The grandmother, $1-1$, had increased concentrations of orotic acid in urine samples obtained before and after the administration of ammonium chloride.

Protein loading tests (Table III) resulted in rapid elevations of orotic acid in urine in the mother, II-6, and the cousin, $I I I-1$. The aunt, $I I-1$, who again became severely ill, had a slower but consistent rise in orotic acid. Protein loading also resulted in a significant elevation of urine orotic acid in the cousin, III-2. The rise in orotic acid in the grandmother, $I-1$, was slower but still significant. Similar protein loads were given to male members of the family $(I I-4, I I I-3$, and $I I I-5)$, but there were no elevations in the concentration of orotic acid in any of the urine specimens.
Table 1II. Protein loading test ${ }^{1}$

\begin{tabular}{|c|c|c|c|}
\hline & \multicolumn{3}{|c|}{ Orotic acid in urine, $\mu \mathrm{g} / \mathrm{mg}$ creatinine } \\
\hline & Fasting & Protein load & $\begin{array}{l}\text { Protein load } \\
\text { minus fasting }\end{array}$ \\
\hline Control subjects & $5.2 \pm 4.42$ & $6.8 \pm 5.54$ & $1.6 \pm 3.0$ \\
\hline $11-6$ (mother) & 6.2 & 86.0 & 79.8 \\
\hline $\begin{array}{l}1-1 \text { (maternal } \\
\text { grandmother) }\end{array}$ & 9.5 & 20.0 & 10.5 \\
\hline $\begin{array}{l}I I-1 \text { (maternal } \\
\text { aunt) }\end{array}$ & 8.0 & 46.0 & 38.0 \\
\hline $\begin{array}{l}\text { II- } 4 \text { (maternal } \\
\text { uncle) }\end{array}$ & 4.8 & 6.3 & 1.5 \\
\hline $\begin{array}{l}I I I-1 \text { (daughter } \\
\text { of } I I-1 \text { ) }\end{array}$ & 14.3 & 73.0 & 58.7 \\
\hline $\begin{array}{l}I I I-2 \text { (daughter } \\
\text { of } l(-I)\end{array}$ & 9.0 & 33.0 & 24.0 \\
\hline $\begin{array}{l}\text { III-3 (half- } \\
\text { brother) }\end{array}$ & 8.9 & 6.3 & 2.6 \\
\hline$I I I-5$ (brother) & 4.9 & 7.2 & 2.3 \\
\hline
\end{tabular}

1 The orotic acid content of urine was the highest in the samples collected within $12 \mathrm{hr}$ of ingesting the high protein meal. Control values were obtained from eight unrelated adult subjects, three males and five females. Control values are given as the mean $\pm \mathrm{sD}$.

\section{Discussion}

We have described a patient with OTC deficiency. The clinical course and pedigree of this patient are similar to that of other male patients with this genetic lesion $[5,12,18,24,26]$, and substantiate the X-linked dominant transmission of the defect with varying degrees of illness in females. The pathogenesis of the disorder has been discussed extensively in previous reviews [5, $6,15,25,29]$.

Because OTC catalyzes the carbamylation of ornithine into citrulline, a deficiency of this enzyme could result in elevated levels of carbamyl phosphate and ornithine. However, these metabolites are not elevated 
in either blood or urine of these patients [13, 25, 29]. Ornithine may be converted to proline or glutamine through the glutamic acid-proline shunt. The concentration of proline in urine has been elevated in some of the patients with OTC deficiency [5, 29], including the patient described in this study, but proline excretion has been inconsistent both in patients with this disease and in control subjects, presumably because of the variable content of this amino acid in the ingested proteins.

Glutamine may also become elevated as the result of increased combination of ammonia with glutamic xcid in some patients with OTC deficiency $[5-7,13$, $15,25]$. However, the concentration of this amino acid in the plasma of carriers has not been elevated consistently enough to be used as a marker to identify the heterozygote $[6,15]$.

Carbamyl phosphate is an intermediate not only in urea biosynthesis, but in de novo pyrimidine biosynthesis as well. Two separate enzymes catalyze the synthesis of carbamyl phosphate: an intramitochondrial carbamyl phosphate synthetase which is found predominantly in liver and subserves urea biosynthesis; and a cytoplasmic carbamyl phosphate synthetase which has more ubiquitous tissue distribution and is presumed to be associated with pyrimidine biosynthesis [11, 27]. Recent data indicate that carbamyl phosphate may leak from mitochondria and be utilized for pyrimidine biosynthesis [30]. Pyrimidine nucleotide biosynthesis is normally controlled by feedback inhibition of the carbamyl phosphate synthetase which subserves the de novo pyrimidine pathway $[16,30]$. However, this control mechanism does not significantly limit the entry of carbamyl phosphate into the pyrimidine pathway in patients with OTC deficiency. The block in OTC may therefore be expected to result in an excess synthesis of pyrimidines, as was found in our patient. The elevation of orotic acid in urine closely followed the increased levels of ammonia in blood. Although it is not clear why orotic acid accumulates rather than other products of the de novo pyrimidine pathway, two explanations are possible: (1) work with rat hepatoma cells has shown that addition of uridine to the culture medium rapidly represses the levels of orotidine pyrophosphorylase in these cells [9]; (2) rat liver orotidine decarboxylase is inhibited by uridine monophosphate [3]. Because the decarboxylase has greater activity than the pyrophosphorylase, and because the $\mathrm{K}_{\mathrm{i}}$ for uridine monophosphate is very high $(7 \mathrm{~mm})$, it is more likely that orotic acid accumulates because of a feedback effect on pyrophosphorylase than on decarboxylase. Asymptomatic orotic aciduria has also been found in heterozygotes of congenital orotic aciduria [17], patients receiving 6 -azauridine [17, 31] and allopurinol [31], normal pregnant women [31], and in some patients receiving parenteral nutrition [28].

Because orotic aciduria accompanied hyperammonemia in the patient with OTC deficiency, orotic acid was measured as an indication of a partial OTC deficiency after ammonia and protein loading in members of the patient's family. Both the mother, an obligate carrier, and an aunt, the only symptomatic female in this pedigree, had hyperammonemia after the ingestion of ammonium chloride (Table II). They also had significant orotic aciduria after a protein load as did the two female cousins whose ammonium tolerance was normal (Table III).

The responses of the males in this pedigree to both loading tests were similar to those of control subjects. The maternal grandmother excreted a large amount of orotic acid in her urine relatively consistently and not necessarily in response to ammonia or protein loading. These data suggest that the two female cousins and the maternal grandmother are asymptomatic female heterozygotes despite their normal ammonium chloride loading tests.

Protein loading in the form of a relatively palatable and innocuous meal followed by determination of orotic acid content in urine may prove to be a sensitive, noninvasive, and easy means to identify female carriers of ornithine transcarbamylase deficiency.

\section{Summary}

We have described and discussed the genetic, clinical, and biochemical aspects of ornithine transcarbamylase (OTC) deficiency. This disorder is probably X-linked, fatal in males, and with a variable degree of illness in female heterozygotes. Although the patient in this study was kept alive for 25 days, and several modes of therapy were employed, there was no indication of OTC induction or any other reversal of the fatal nature of this illness. Orotic acid concentration in the urine of the patient very closely paralleled the concentration of ammonia in his blood. Concentration of orotic acid in urine of the family members was determined in an attempt to accurately and easily identify female heterozygotes of OTC deficiency. Our results indicate that a high protein meal followed by determinations of orotic acid in urine specimens collected for 
$12 \mathrm{hr}$ thereafter is a sensitive and noninvasive means of diagnosis. It is possible that three asymptomatic females in this pedigree who had normal tolerance to ammonium chloride are carriers of OTC deficiency as demonstrated by this method.

\section{References and Notes}

1. Adachi, T., Tanimura, A., and Asahina, M.: A colorimetric determination of orotic acid. J. Vitaminol., 9: 217 (1963).

2. Bessman, S. P., and Bessman, A. N.: The cerebral and peripheral uptake of ammonia in liver disease with an hypothesis for the mechanism of hepatic coma. J. Clin. Invest., 34: 622 (1955).

3. BLAIR, D. G. R., AND POTter, V. R.: Inhibition of orotidylic acid decarboxylase by uridine 5'-phosphate. J. Biol. Chem., 236: 2503 (1961).

4. Bruton, C. J., Corsellis, J. A. N., and Russell, A.: Hereditary hyperammonaemia. Brain, 93: 423 (1970).

5. Campbell, A. G .M., Jr., Rosenberg, L. E., SNodgrass, P. J., AND Nuzum, C. T.: Ornithine transcarbamylase deficiency: A cause of lethal neonatal hyperammonemia in males. New Engl. J. Med., 288: 1 (1973).

6. Colombo, J. P.: Congenital disorders of the urea cycle and ammonia detoxication. Monogr. Paediat., 1: 1 (1971).

7. Corbeel, L. M., Colombo, J. P., Van Sande, M., and Weber, A.: Periodic attacks of lethargy in a baby with ammonia intoxication due to a congenital defect in ureogenesis. Arch. Dis. Childhood, 44: 681 (1969).

8. Henre, R. J.: Clinical Chemistry: Principles and Techniques, p. 287 (Hocber Medical Division, Harper and Row, New York, 1964).

9. HoogenraAd, N. J., And Lee, D. C.: Effect of uridine on de novo pyrimidine biosynthesis in rat hepatoma cells in culture. J. Biol. Chem., 1196 (1973).

10. Hopkins, I. J., Connelly, J. F., Dawson, A. G., Hird, F. J. R., ANd Maddison, T. G.: Hyperammonaemia due to ornithine transcarbamylase deficiency. Arch. Dis. Childhood, 44: 143 (1969).

11. Jones, M. E.: Regulation of pyrimidine and arginine biosynthesis in mammals. Advan. Enzyme Regul., 9: 19 (1971).

12. Kang, E. S., SNodgrass, P. J., and Gerald, P. S.: Ornithine transcarbamylase deficiency in the newborn infant. J. Pediat., S2: 642 (1973).

13. Levin, B., Abraham, J. M., Oberholzer, V. G., and Burgess, E. A.: Hyperammonaemia: A deficiency of liver ornithine transcarbamylase. Occurrence in mother and child. Arch. Dis. Childhood, 44: 152 (1969).

14. Levin, B., Dobbs, R. H., Burgess, E. A., and Palmer, T.: Hyperammonaemia: A variant type of deficiency of liver ornithine transcarbamylase. Arch. Dis. Childhood, 44: 162 (1969).

I5. Levin, B., Oberholzer, V. G., and Sinclatr, L.: Biochemical investigations of hyperammonaemia. Lancet, 2: 170 (1969).

16. Levine, R. L., HoogenraAd, N. J., ANd Kretchimer, N.: Regulation of activity of carbamoyl phosphate synthetase from mouse spleen. Biochemistry, 10: 3694 (1971).

17. Lotz, M., Fallon, H. J., and Smith, L. H.: Excretion of orotic acid and orotidine in heterozygotes of congenital orotic aciduria. Nature, 197: 194 (1963).
18. MacLeod, P., Mackenzie, S., and Scriver, C. R.: Partial ornithine carbamyl transferase deficiency: An inborn error of the urea cycle presenting as orotic aciduria in a male infant. Can. Med. Ass. J., 107: 405 (1972).

19. Marsuda, I., Arashima, S., Nambu, H., Takekoshi, Y., and Anakura, M.: Hyperammonemia due to a mutant enzyme of ornithine transcarbamylase. Pediatrics, 48: 595 (1971).

20. O'Brien, D., Ibbott, F. A., And Rodgerson, D. O.: Laboratory Manual of Pediatric Micro-Biochemical Techniques, Ed. 4, p. 277 (Hoeber Medical Division, Harper and Row, New York, 1968).

21. Rogers, L. E., And Porter, F. S.: Hereditary orotic aciduria. II. A urinary screening test. Pediatrics, 42: 423 (1968).

22. Russell, A., Levin, B., Oberholzer, V. G., and Sinclatr, L.: Hyperammonaemia. A new instance of an inborn enzymatic defect of the biosynthesis of urea. Lancet, 2: 699 (1962).

23. Saudubray, J. M., Cathelineau, L., Charpentier, C., Borsse, J., Allaneau, C., Le Bont, H., and Lesage, B.: Deficit hereditaire en ornithine-carbamyl-transferase avec anomalie enzymatique qualitative. Arch. Franc. Pediat., 30: 15 (1973).

24. Scott, C. R., Teng, C. C., Goodman, S. I., Greensher, A., AND MACE, J. W.: X-linked transmission of ornithine-transcarbamylase deficiency. Lancet, 2: 1148 (1972).

25. Shit, V. E., And Erron, M. L.: Urea cycle disorders. In: J. B. Stanbury, J. B. Wyngaarden, and D. S. Fredrickson: The Metabolic Basis of Inherited Disease, Ed. 3, Chapt. 17, p. 370 (McGraw Hill Book Company, New York, 1972).

26. Short, E. M., Conn, H. O., Snodgrass, P. J., Campbell, A. G. M., JR., AND Rosenberg, L. E.: Evidence of X-linked dominant inheritance of ornithine transcarbamylase deficiency. New Engl. J. Med., 288: 7 (1973).

27. SMrrн, L. H.: Pyrimidine metabolism in man. New Engl. J. Med., 288: 764 (1973).

28. Sunshine, P., Johnson, J. D., And Hoogenraad, N. J.: Unpublished data.

29. Sunshine, P., Lindendaum, J. E., Levy, H. L., and Freeman, J. M.: Hyperammonemia due to a defect in hepatic ornithine transcarbamylase. Pediatrics, 50: 100 (1972).

30. Tatibana, M., AND ITo, K.: Carbamyl phosphate synthetase of the hematopoietic mouse spleen and control of pyrimidine biosynthesis. Biochem. Biophys. Res. Commun., 26: 221 (1967).

31. Wood, M. H., and O'Sullivan, W. J.: The orotic aciduria of pregnancy. Amer. J. Obstet. Gynecol., 116: 57 (1973).

32. New England Nuclear Corporation, Boston, Mass. (specific activity $16.5 \mathrm{mCi} / \mathrm{mmol}$ )

33. New England Nuclear Corporation, Boston, Mass.

34. Beckman Instruments, Palo Alto, Calif.

35. Informed consent was obtained from all subjects and parents of minor subjects in this study.

36. The authors gratefully acknowledge Bruce Tune, M.D., for guiding our management of the patient, Jean-Jaques Cassiman, M.D., for analyses on amniotic fluid samples, and Toshiyuki Ando, M.D., and William L. Nyhan, M.D., for performing the analysis on the urine of subject III-7.

37. Dr. A. S. Goldstein was a recipient of a fellowship under the auspices of the National Institutes of Health Training grant no. HD-00049. Dr. E. Swierczewski was a participant in an exchange agreement under the auspices of the John E. Fogarty International Center and National Institutes of Child Health and Human Development of the National Institutes 
of Health and the French Foreign Office in conjunction with INSERM (FR).

38. This investigation was supported by Grant no. RR-81 from the General Clinical Research Centers Program of the Divisions of Research Resources, National Institutes of Health, Research Grant no. HD-02147 and Training Grant no. HD-
00049 from the National Institutes of Health, and a grant from the National Foundation-March of Dimes.

39. Requests for reprints should be addressed to: PHILIP SUNShrne, M. D., Department of Pediatrics, Stanford University Medical Center, Stanford, Calif. 94305 (USA).

40. Accepted for publication August 24, 1973. 